\title{
Distribution plan for kidney donations stirs ethical debate in United States
}

$\mathrm{T}$ o Americans, the notion of medical rationing is distinctly un-American. They hold firmly to the ethic that everyone should have an equitable shot at treatment and cures, even if that ideal holds up far better in theory than in practice.

Now, a proposed overhaul of the US kidney donation system has put the uncomfortable question of rationing squarely in the face of policy-makers and medical professionals.

It's a debate likely to become familiar across the landscape of US health care as the medical system grapples with overbearing demands from an aging population, as well as an expected surge in patients resulting from the expansion of insurance in President Barack Obama's health care law.

In short, the proposal is to match the best $20 \%$ of kidneys from deceased donors with the $20 \%$ of recipients who are most likely to live the longest with those organs. The remaining $80 \%$ of kidneys and patients would be paired largely as they are now, by a standard waiting list adjusted for geographic location and a few other factors.

The changes were proposed in September by a committee of the United Network for Organ Sharing (UNOS), a nonprofit organization that manages the national organ transplant system under contract with the federal government, and could be adopted as early as June (http://optn.transplant .hrsa.gov/PublicComment/pubcomment PropSub_311.pdf).

Proponents see the $20-80$ policy as the key to making more efficient use of scarce organs. It makes no sense, they say, to put a kidney likely to last five years in a young, otherwise healthy recipient bound to live many more decades. That patient will be back, probably several times, for more transplants, further straining a system of supply and demand that is already having difficulties.

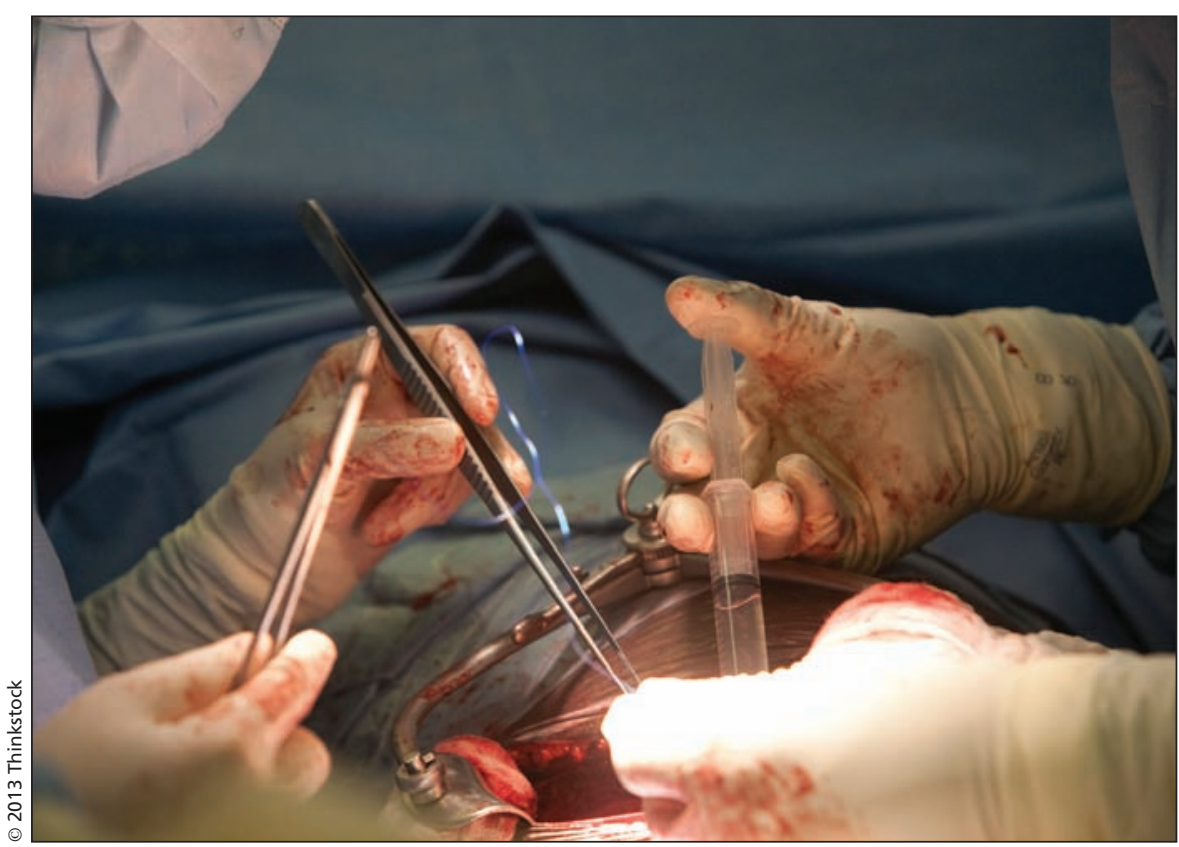

It makes no sense, say organ transplant experts, to put a kidney likely to last five years in a young, otherwise healthy recipient bound to live many more decades.

To critics, the new system would establish an organ-transplant elite, relegating the bulk of recipients to secondtier status.

Dr. Dan Bustillos, an assistant professor at Saint Louis University's Albert Gnaegi Center for Health Care Ethics in St. Louis, Missouri, sees both sides and no easy answers.

"Tough decisions and imperfect solutions are unavoidable when the constraints are such as they are in this scenario," says Bustillos.

The $20-80$ policy "might be a viable though controversial strategy to squeeze the most benefit out of an extremely limited resource," he says. But officials must ensure "everyone's voice is heard and that we listen especially to those whose chances at receiving this life-giving organ will be diminished by the policy."

Bobbi Wager, 55, a San Antonio, Texas, nurse and renal-care coordinator, counts herself in that disadvantaged group. Diagnosed with end-stage renal disease in 1982 and told she had two months to live, Wager received two kidney transplants, from her brother in 1983 and her husband in 1998.

"I have been blessed," she says. "I have not had to go on the waiting list for a kidney transplant. But I am a realist. I will someday be faced with being put on a waiting list to be given another chance at life."

And she rates her odds of getting one as dim if the proposal becomes policy. "I think the transplant community is trying to cherry pick whom should be transplanted and whom should not be transplanted."

More than 93000 people are listed for kidney transplantation nationwide, UNOS stated in announcing the proposal, and $10 \%$ die each year while waiting. The group estimates an additional 8380 years of life could be achieved annually with more efficient distribution of the pool of deceased donor kidneys.

It's all but certain more prime organs would go to the young in the 
revamped system and older people could face stiffer competition for a transplant. Although the goal is to increase efficiency, that may not happen, says Dr. Lainie Ross, a bioethicist at the University of Chicago in Illinois.

She says people aged 18-25 are the least compliant about taking their immunosuppression medicine, so may be more apt to lose the kidney prematurely. And young adults are the most likely to get a living kidney donor. "By giving them preferential treatment for a deceased donor kidney, you may give them less incentive to seek out a living donor," she says. So it is possible to end up with fewer donor kidneys overall.

Bustillos puts the essential ethical question this way: "Should a new allocation policy be in keeping with the American ethos of respecting our elders, or will America's fascination with youth win out?"

The potential implications are broad because almost every field of medicine deals with scarcity, whether it's in the supply of primary care physicians, skilled nurses, critical care beds, mechanical ventilators or more. Hard choices are commonplace. So is rationing of one sort or another.
Is $20-80$, then, a slippery slope?

For decades now, says Bustillos, "we have chosen to go down the slope and stop at a particular place somewhere below the summit and above the imagined horrors of the valley. My observation is that history has shown it is quite possible to stop without barreling downslope uncontrollably."

"Will this policy, if adopted, necessarily devolve into something more sinister? Probably not. Is it prudent or ethical to go this far? I'm not convinced." - Cal Woodward, Washington, DC

CMAJ 2013. DOI:10.1503/cmaj.109-4424 